\title{
STATIC AND FATIGUE BEHAVIOR OF CFRP-STRENGTHENED RC BRIDGE GIRDERS SUBJECTED TO VEHICLE OVERLOADING
}

\author{
Xiao-Yan Sun ${ }^{1}$, Jian-Guo Dai ${ }^{2}$, Hai-Long Wang ${ }^{1,}{ }^{*}$ and Chong $\mathrm{Xu}^{3}$ \\ ${ }^{1}$ Department of Civil Engineering, Zhejiang University, Hangzhou, China. \\ ${ }^{2}$ Department of Civil and Environmental Engineering, The Hong Kong Polytechnic University, Hong Kong, China. \\ ${ }^{3}$ Hanjia Design Group of China, Hangzhou 310005, China \\ *(Corresponding author: Email: hlwang@zju.edu.cn)
}

\begin{abstract}
This paper presents an experimental study into the static and fatigue behavior of three pairs of small-scaled reinforced concrete (RC) bridge girders, in order to investigate the influences of overloading on the fatigue strengthening effects of externally bonded carbon fiber reinforced polymer (CFRP) laminates and understand the mechanisms of fatigue damage accumulation in CFRP-strengthened RC bridge girders under vehicle overloading. Two pairs were strengthened with CFRP laminates and the remained one pair was un-strengthened as references. Two types of overloading were implemented in this test program: one was overloading both prior to and after FRP strengthening and the other was cyclic overloading only after FRP strengthening. At the end of the cyclic overloading all the girders were tested under monotonic loading until failure. Through the evaluation of the pre-fatigue static strength, the development of deflection and cracks during the fatigue loading and the post-fatigue strength of both un-strengthened and CFRP-strengthened RC girders, the effects of the above two different types of overloading on their static and fatigue behaviors are extensively discussed.
\end{abstract}

Keywords: RC girders, CFRP, Strengthening, Overloading, Fatigue

DOI: $10.18057 /$ IJASC.2015.11.3.9

\section{INTRODUCTION}

Reinforced concrete (RC) bridge structures designed for public traffic service usually need to experience millions of loading cycles over their service life. To guarantee the fatigue safety of an $\mathrm{RC}$ bridge structure, the load level under a service condition needs to be well controlled so that the working stress in steel reinforcement is lower than a threshold value (e.g., $60 \%$ of the yield strength of steel reinforcement) according to AASHTO [1]. However, Karabinis and Kiousis [2] found that the high stress amplitude in steel reinforcement may often exceed the recommended service load level because of the ever-increasing vehicle transportation demand. Sun et al. [3] monitored the structural behavior of a $25 \mathrm{~m}$ span simply-supported RC girder bridge in China on basis of the in-situ traffic survey data and found that the maximum stress in the longitudinal reinforcement may reach up to about $85 \%$ of its yield strength. Usually the vehicle overloading does not cause an RC bridge to collapse instantly, but the high stress amplitude caused by overloading will definitely accelerate the damage accumulation and the structural performance degradation in critical details [4]. In both USA and China, Hersi [5], Ji and $\mathrm{Fu}$ [6] found that vehicle overloading has become a major factor leading to the failure of bridge structures (Figure1 and Figure 2).

Use of externally bonded fiber reinforced polymer (FRP) composites has proven to be a cost-effective method for the flexural strengthening of RC bridge structures for both static (Grace et al.[7], Pham and Al-Mahaidi[8], Esfahania et al.[9], Wang et al.[10,11]) and fatigue enhancement purposes (Xie et al.[12], Dong et al.[13], Ferrier et al.[14]). It has been recognized that the FRP strengthening can improve the strength of existing RC members, decrease the stress level in steel 
reinforcement under service load and thus improve their fatigue performance. However, very little has been explored on the fatigue performance of FRP-strengthened RC beams subjected to cyclic overloading. Breña et al. [15] compared the fatigue life of no pre-damaged carbon FRP(CFRP)-strengthened beams under a high stress level (i.e., $90 \%$ of the rebar yield strength) with that under a normal service load level (i.e., below $60 \%$ of the rebar yield strength), found that the fatigue life of CFRP-strengthened beam was decreased sharply in the former case. Al-Hammoud et al.[16] investigated the fatigue flexural behavior of CFRP-strengthened beams pre-damaged with rebar corrosion and found that, while the pre-corrosion damage the same, the higher stress amplitude (e.g., $80 \%$ of the rebar yield strength) led to a reduction of the fatigue life down to $13 \%-19 \%$ of that under a normal service load level (e.g., $60 \%$ of the rebar yield strength). Al-Rousan and Issa [17] conducted an experimental program to investigate the static response of non-pre-damaged CFRP-strengthened beams after cyclic loading of different stress amplitude. They found that the high stress range had a significant effect on the permanent deflection at mid-span, especially for the stress range of $45-90 \%$ of the rebar yield strength.

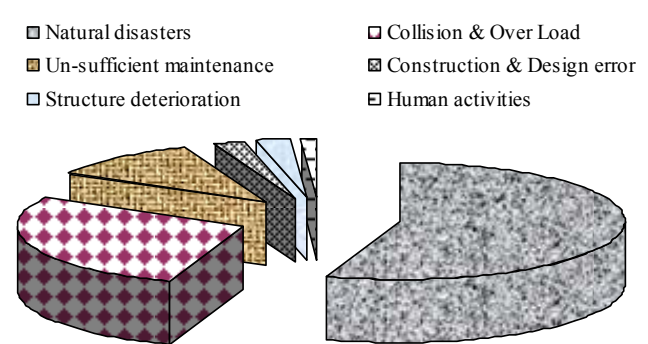

Figure 1. Statistics of Bridge Failures in USA (2000-2008) (Hersi [5])

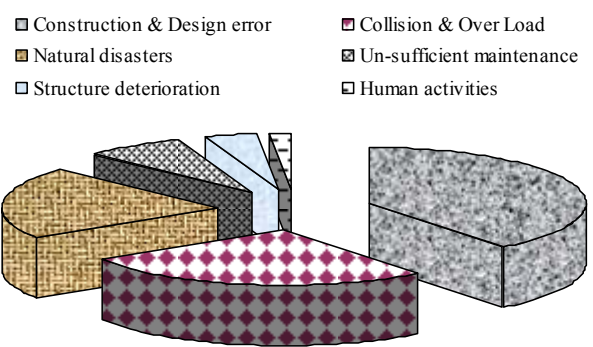

Figure 2. Statistics of Bridge Failures in China (2000-2010) (Ji and Fu [6])

This paper aims to conduct an experimental study to investigate: (1) the fatigue behavior of un-strengthened and CFRP flexurally strengthened RC beams subjected to cyclic overloading; and (2) the static and fatigue behavior of CFRP flexurally strengthened RC beams with initial overloading damage prior to the CFRP strengthening.

\section{EXPERIMENTAL PROGRAM}

\subsection{Details of Specimens}

Six RC beams with a rectangular cross section of $150 \times 300 \mathrm{~mm}$ and a testing span of $2400 \mathrm{~mm}$ were prepared in this study (Figure 3a). Each beam was reinforced with two tensile deformed bars of $16 \mathrm{~mm}$ in diameter, which had a concrete cover of $25 \mathrm{~mm}$, two round bars $8 \mathrm{~mm}$-diameter in the compressive zone, and steel stirrups of $8 \mathrm{~mm}$ in diameter and $100 \mathrm{~mm}$ in spacing (Figure 3a).
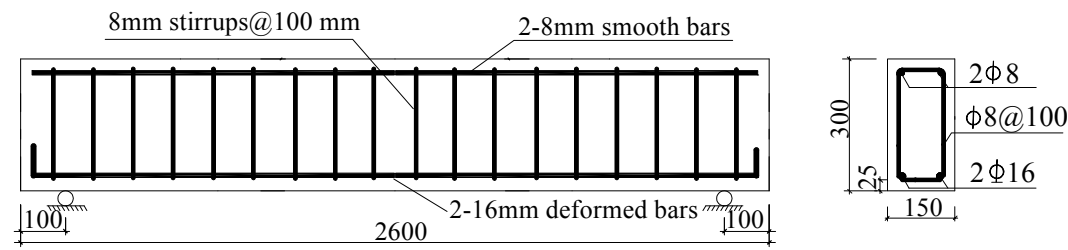

(a) Beam Geometry and Reinforcement Information 


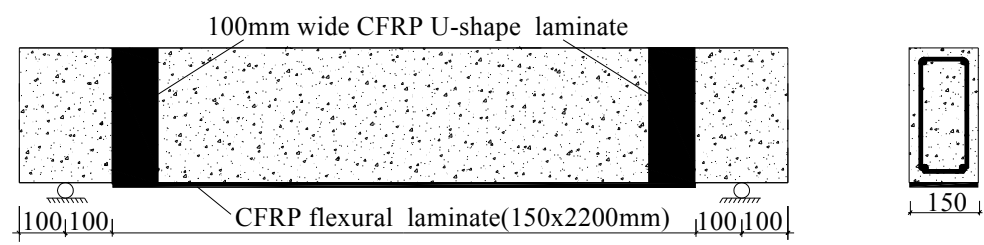

(b) FRP Reinforcement Information

Figure 3. Details of Test Beams (unit: mm)

Among the six RC beams, four beams were externally strengthened in flexure with one layer of unidirectional CFRP sheet and two beams were un-strengthened as control specimens (see Table 1). As shown in Figure 3b, the CFRP sheet was $150 \mathrm{~mm}$ wide and $2200 \mathrm{~mm}$ long. Two U-shape anchorages were installed at the two ends of the CFRP sheet to prevent plate-end failure. Table 1 presents a summary of all the specimens. Beams $\mathrm{BC} 0$ and $\mathrm{BC} 1$ were un-strengthened. $\mathrm{BC} 0$ was loaded under monotonic static loading until failure while $\mathrm{BC} 1$ was cyclically overloaded before the monotonic static loading test. Beams BR0 and BR1 were all strengthened with 1 layer of CFRP sheet, and their loading schemes were the same as those of $\mathrm{BC} 0$ and $\mathrm{BC} 1$, respectively. Beams BD0 and BD1 are similar to beams BR0 and BR1 except that they had experienced initial overloading damage prior to CFRP strengthening. This initial damage caused the yielding of tensile steel reinforcement as shown in Figure 4. At the end of overloading, the width of the major crack (i.e. the one that had the maximum crack width) reached $1.0 \mathrm{~mm}$.

Table 1. Summary of Test Specimens

\begin{tabular}{cccc}
\hline $\begin{array}{c}\text { Specimen } \\
\text { code }\end{array}$ & $\begin{array}{c}\text { Initial } \\
\text { damage }\end{array}$ & $\begin{array}{c}\text { Strengthening } \\
\text { scheme }\end{array}$ & Loading type \\
\hline BC0 & None & None & Monotonic static loading \\
\hline BC1 & None & None & $\begin{array}{c}\text { Cyclic overloading }+ \\
\text { Monotonic static loading }\end{array}$ \\
\hline BR0 & None & CFRP sheet & Monotonic static loading \\
\hline BR1 & None & CFRP sheet & $\begin{array}{c}\text { Cyclic overloading }+ \\
\text { Monotonic static loading }\end{array}$ \\
\hline BD0 & Overloaded & CFRP sheet & Monotonic static loading \\
\hline BD1 & Overloaded & CFRP sheet & $\begin{array}{c}\text { Cyclic overloading }+ \\
\text { Monotonic static loading }\end{array}$ \\
\hline
\end{tabular}

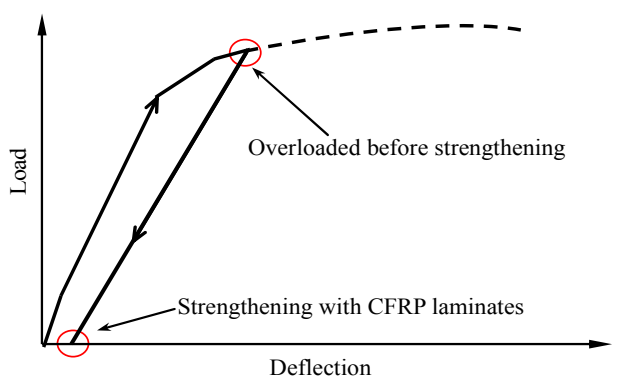

Figure 4. Introduction of Initial Overloading Damage Prior to FRP Strengthening 


\subsection{Materials Properties}

The $16 \mathrm{~mm}$ deformed reinforcement in tension had a yield strength of $335 \mathrm{MPa}$ and an elastic modulus of $200 \mathrm{GPa}$. The $8 \mathrm{~mm}$ round bar used as shear reinforcement exhibited a yield strength of $235 \mathrm{MPa}$ and an elastic modulus of $210 \mathrm{GPa}$. The concrete was a ready-mixed type provided by a local plant and had a cube compressive strength of $30 \mathrm{MPa}$. The CFRP sheet used in the tests had a nominal thickness of $0.111 \mathrm{~mm}$. Its ultimate tensile strength and elastic modulus were $3500 \mathrm{MPa}$ and $230 \mathrm{GPa}$, respectively.

\subsection{Loading Scheme and Testing Procedure}

All the beams were subjected to four-point bending over a simply supported span of $2400 \mathrm{~mm}$ as shown in Figure 5a. An $800 \mathrm{~mm}$ long constant moment zone existed in the middle part of the beams. The monotonic and fatigue loads were applied onto the beams using an MTS machine, as illuminated in Figure 5b. During the production of the beams, optic fiber sensors were embedded in the beams to monitor the strains of concrete (see locations $F_{c 1}$ and $F_{c 2}$ in Figure 5a) and steel reinforcement (see locations $\mathrm{F}_{\mathrm{s} 1}$ and $\mathrm{F}_{\mathrm{s} 2}$ in Figure 5a). Prior to the tests, three gauges were also placed on the concrete surface at the heights of $250 \mathrm{~mm}, 200 \mathrm{~mm}$ and $150 \mathrm{~mm}$, respectively, from the top of the beam (Figure 5a). In addition, three gauges were attached on the surface of CFRP sheet within the constant moment zone (Figure 5a). Three linear voltage displacement transducers (LVDTs) were installed at the mid-span and support locations to obtain the mid-span deflection. During the tests, all the loads, displacement and strains were recorded using a data acquisition system.

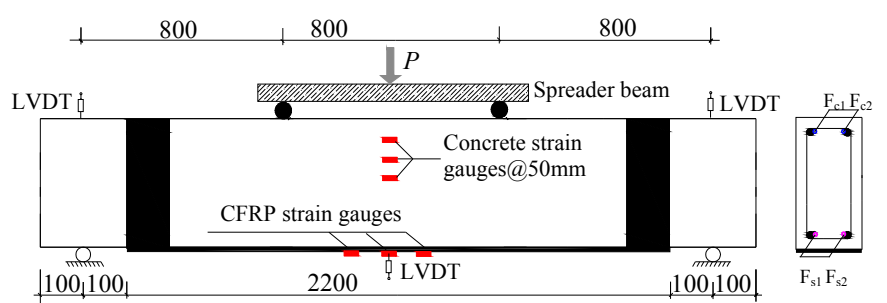

(a) Four-point Loading Diagram

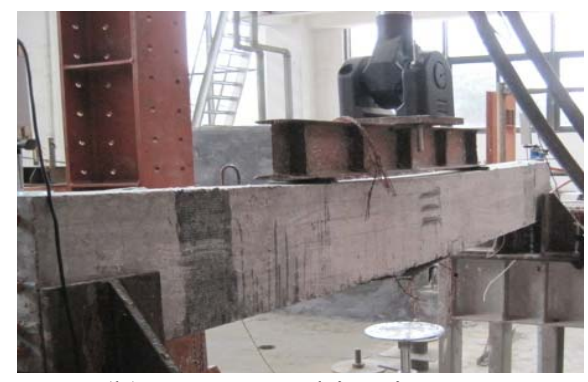

(b) MTS Machine in Test

Figure 5. Test Set-up (unit: $\mathrm{mm}$ )

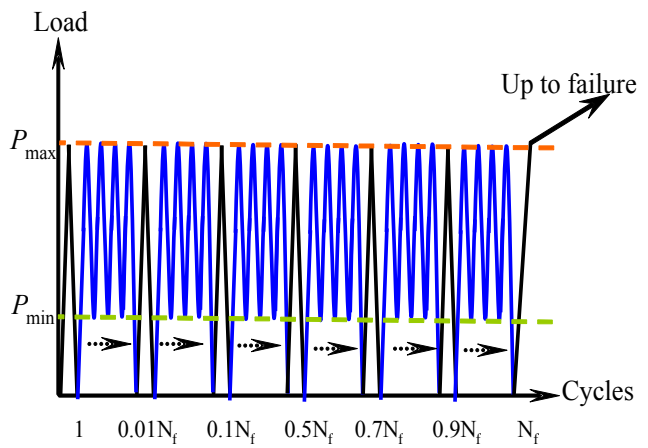

Figure 6. Loading Sequence of Fatigue Tests

As mentioned previously, there were two loading schemes: monotonic static loading and cyclic overloading. The un-strengthened control beam was loaded monotonically to failure to identify its ultimate load $\left(P_{\mathrm{u}}\right)$ firstly. Then the load sequence for fatigue tests was implemented as shown in 
Figure 6. During the fatigue tests, the upper bound load (i.e., $P_{\max }$ ) was set as $0.8 P_{u}$ and the low bound load (i.e., $P_{\min }$ ) was set as $0.35 P_{u}$ for both un-strengthened and CFRP-strengthened RC beams according to the in-situ survey carried out by Sun [3]. The fatigue loading was applied using a form of sinusoidal wave with a frequency of $2 \mathrm{~Hz}$ and the total number of fatigue cycles $N_{\mathrm{f}}$ was set as 10000 in the tests. Since it was difficult to record all the strain and deflection information during the whole fatigue loading period, the fatigue tests were stopped at certain numbers of fatigue cycles (i.e. $1^{\text {st }}, 0.01 N_{f}, 0.1 N_{f}, 0.5 N_{f}, 0.7 N_{f}, 0.9 N_{f}$, and $N_{f}$ ). At these cycles, all the beams were unloaded and then reloaded to $0.8 P_{\mathrm{u}}$ and the structural responses including the sectional strains, deflections, crack patterns and the maximum crack widths were measured. At the end of the fatigue cycles, all the beams were loaded monotonically to failure.

\section{RESULTS AND DISCUSSION}

\subsection{Static Responses}

\subsubsection{Failure modes}

The control beam $\mathrm{BC} 0$ failed in a typical flexural mode by concrete crushing long after the yielding of steel reinforcement. The CFRP-strengthened RC beam BR0 failed due to the mid-span debonding of CFRP sheet (Figure 7a). However, the other CFRP-strengthened RC beam BD0, which experienced initial overloading damage, failed due to the fracture of CFRP sheets at the location of the maximum crack before the interfacial debonding (Figure $7 \mathrm{~b}$ ). It should be mentioned that the cracks in concrete due to overloading were sealed with epoxy resins prior to the strengthening of the beam BD0 and BD1. The CFRP-strengthened RC beam BR1, which experienced cyclic overloading, failed due to the mid-span debonding of CFRP sheet followed by its brittle rupture (Figure 7c). The CFRP-strengthened RC beam BD1, which experienced initial overloading damage and then cyclic overloading, exhibited the similar failure mode (Figure $7 \mathrm{~d}$ ) as beam BR1.

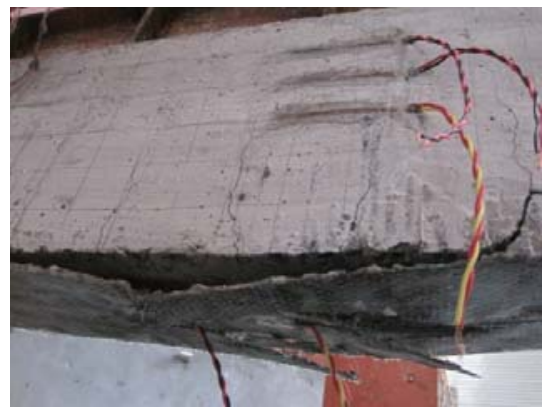

(a) Beam BR0

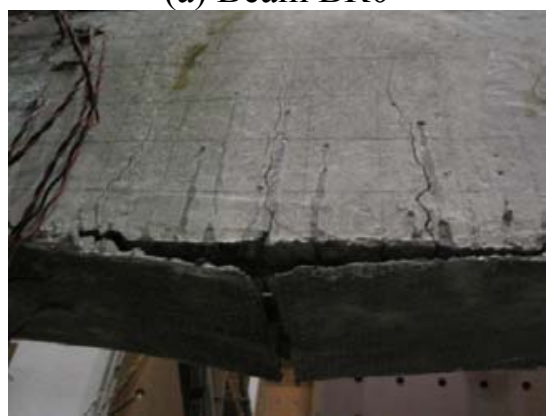

(c) Beam BR1

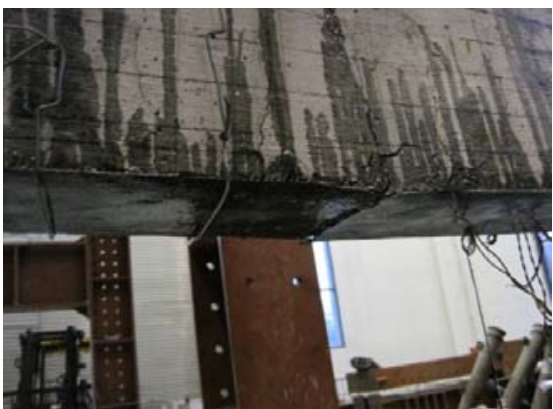

(b) Beam BD0

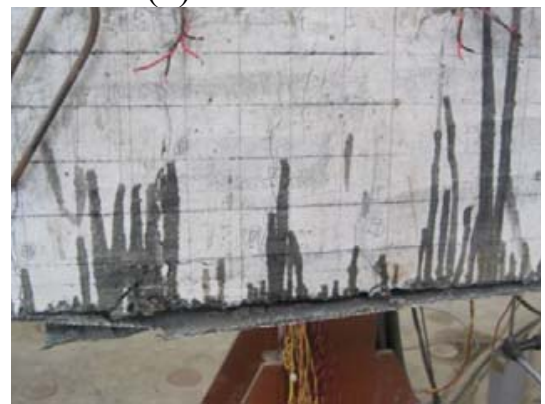

(d) Beam BD1 
Figure 7. Failure Modes of CFRP-strengthened RC Beams under Monotonic Static Loading and Fatigue Loading

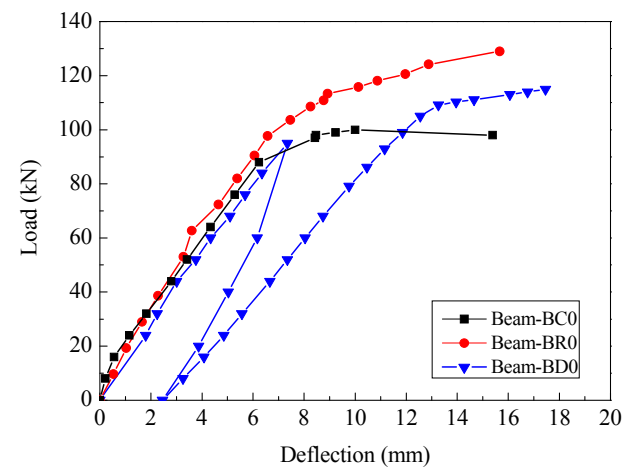

Figure 8. Load-deflection Responses of Beams Tested under Monotonic Loading

\subsubsection{Load-deflection responses}

Figure 8 shows the load-deflection responses of beams BC0, BR0 and BD0 tested under monotonic static loading. It is shown that the beams $\mathrm{BC} 0$ and $\mathrm{BR} 0$ exhibited the similar load-deflection responses till the yielding of steel reinforcement while the latter had a slightly larger bending stiffness. Compared to BC0, BR0 achieved an increased ultimate strength by $29 \%$ due to the FRP strengthening effect. At all the loading stages, beam BD0 experienced larger mid-span deflections than BR0 due to the initial damage induced by the overloading prior to the FRP strengthening (Figure 8). Due to the presence of significant plastic deformation before the FRP strengthening, the ultimate load achieved by the beam BD0 was obviously less than that achieved by the beam BR0. Compared to the un-strengthened beam $\mathrm{BC} 0$, beam $\mathrm{BD} 0$ only achieved an increase in the ultimate strength by $15 \%$.

\subsubsection{Strain development}

Figures 9a-9c shows the development of strains in CFRP, steel reinforcement and concrete with the load. It is shown that at the same load level, the strain in steel reinforcement was decreased in case of FRP-strengthened RC beams as expected. In beam BD0, there was a strain delay in FRP at the early loading stage due to the initial overloading damage. While later on, the strain development in FRP was more rapid than that in steel reinforcement in both BR0 and BD0 beams, which followed the plane sectional assumption. It is interesting to find that the strain development of FRP in beam BD0 was more rapid than that in beam BR0 at the latter loading stage (Figure 9d). This is probably because of the strain localization of FRP at the location of the major crack caused by the initial overloading damage. This also explains why the rupture of FRP occurred in beam BD0 rather than the debonding of FRP as observed in beam BR0 at the ultimate state.

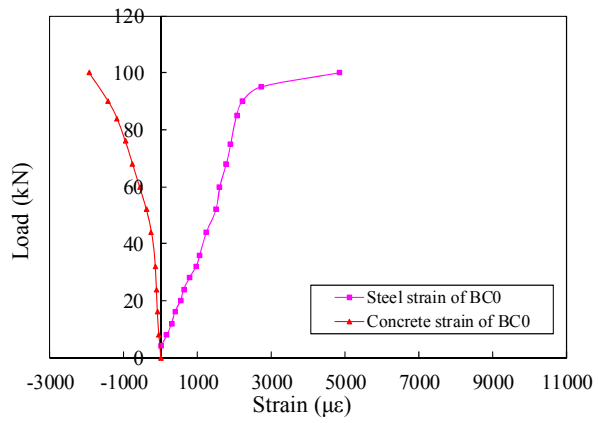

(a)Beam BC0

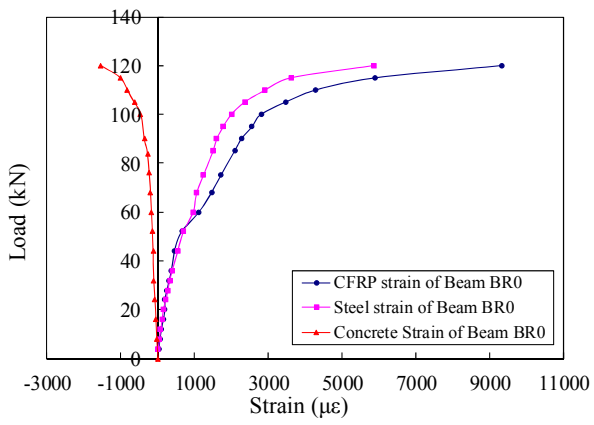

(b) Beam BR0 


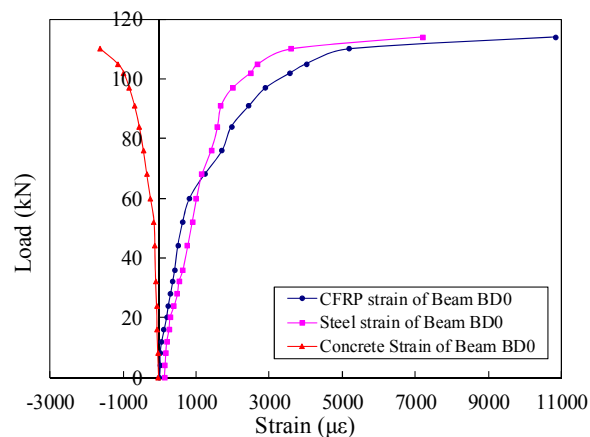

(c) Beam BD0

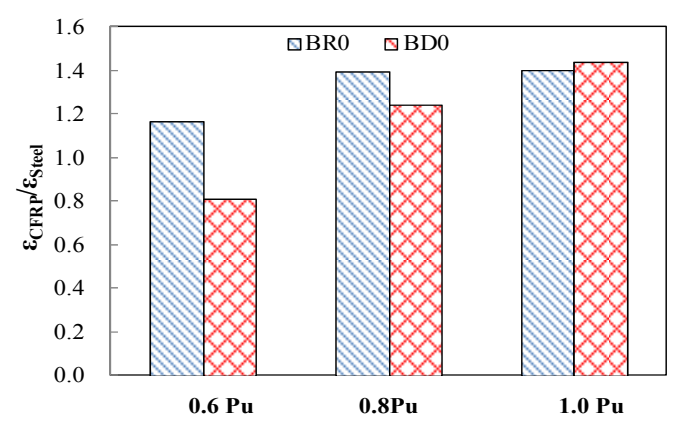

(d) Ratio of CFRP Strain to Tensile Steel Strain

Figure 9. Strain Development in FRP, Concrete and Reinforcement under Monotonic Loading

\subsection{Fatigue Responses}

\subsubsection{Crack propagation}

The developments of cracks were monitored during the test. In the control beam, the cracks started from the bottom of the beam and propagated vertically toward the top of test beam. The number of cracks and the propagation depth depend on the number of fatigue cycles. In beam BR1, the cracking pattern was identical to that in the control beam under the first monotonic load. However, the number, the width, and the depth of cracks were all decreased due to the presence of CFRP laminates. Under cyclic overloading, the cracking depth and width evolved with fatigue cycles. As the increase of applied fatigue cycles, some new cracks developed between the original ones caused by the initial monotonic loading, as shown in Figure 10a. For the overloaded beam BD1, the cracks propagated differently from that of beam BR1 over the fatigue period, as illuminated in Figure $10 \mathrm{~b}$. All cracks developed along the original ones in beam BD1, and no new crack initiated during the fatigue loading period.

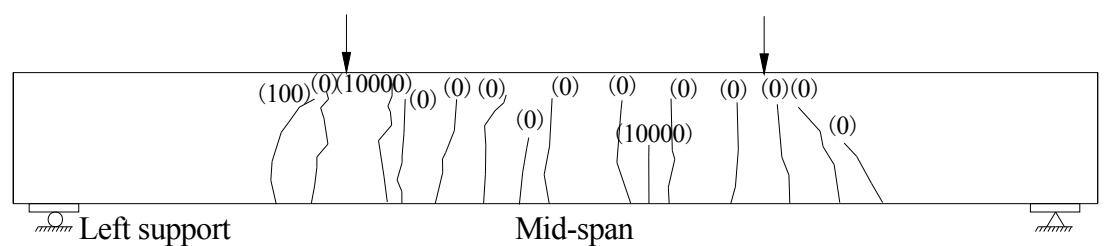

(a) Beam BR1

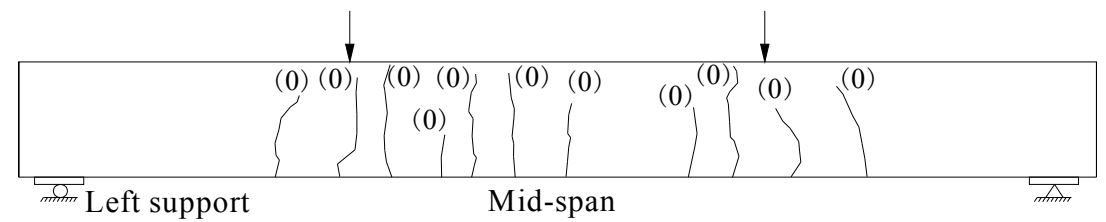

(b) Beam BD1

Figure 10. Crack Propagation in Beams under Fatigue Loading (Digits in Brackets Represent the Number of Fatigue Cycles)

\subsubsection{Load-deflection responses during cyclic loading}

Figure 11 shows the load-deflection hysteresis loops of all the beams, which were obtained after certain numbers of fatigue loading cycles. The seven hysteresis loops in Figures 11a to 11c 
represent the structural responses of beams $\mathrm{BC} 1, \mathrm{BR} 1$ and $\mathrm{BD} 1$, respectively, after having experienced $0,100,1000,5000,7000,9000$ and 10000 cycles of fatigue overloading. It is seen that the mid-span deflections of both un-strengthened and FRP-strengthened beams exhibited remarkable increases and the stiffness exhibited remarkable degradation with the increase of the loading cycles, indicating there was a significantly negative impact of overloading on the fatigue life of the RC beams. However, the accumulation of fatigue damage with the number of cycles was found to be much slower when the maximum fatigue stress in steel reinforcement is below $65 \%$ of its yielding strength (Al-Rousan and Issa[17], Gheorghiu et al.[18]).

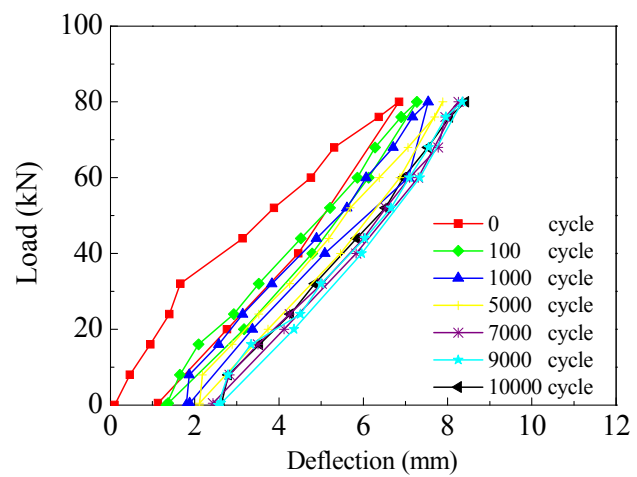

(a) Beam-BC1

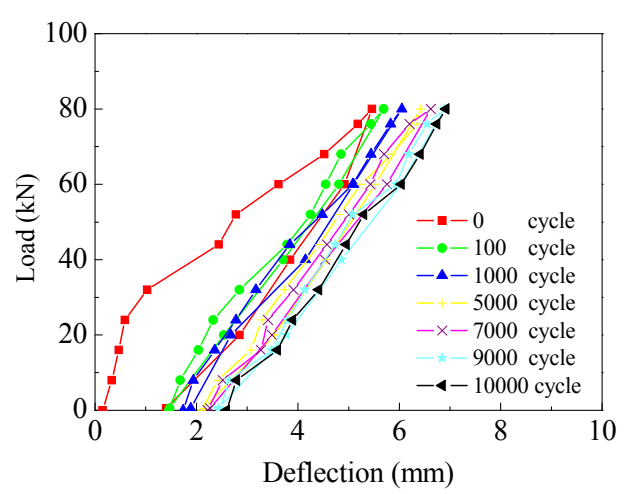

(b) Beam-BR1

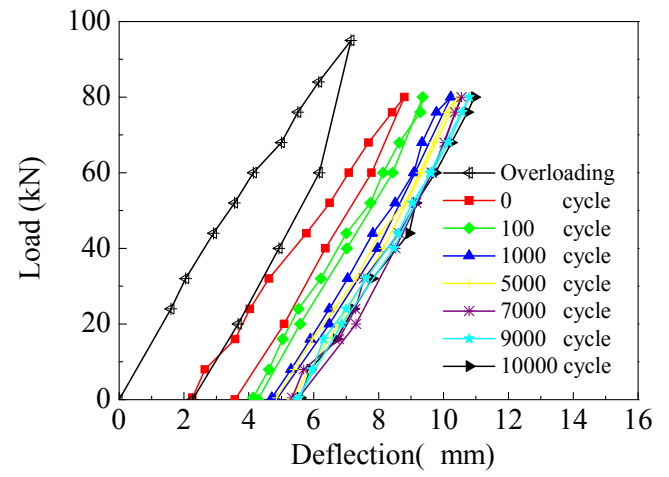

(c) Beam-BD1

Figure 11. Load-deflection Responses of Beams under Fatigue Loading

The unrecoverable plastic deformation can be a useful index to assess the damage accumulation of $\mathrm{RC}$ beams under fatigue loading. Figures $12 \mathrm{a}$ to $12 \mathrm{c}$ present the evolution of the maximum mid-span deflection, and the residual mid-span deflection as well as their ratio with the number of fatigue cycles. It is shown that for both un-strengthened and strengthened beams, the maximum and residual deflections increased rapidly at the beginning and then increased stably with the number of fatigue cycles. Although the maximum deflection of beam BR1 was smaller than that of beam BC1, the residual deflections of two beams were the similar. This implies that the improvement of beam stiffness due to FRP strengthening under an overloading condition is more significant as compared to that under a normal service load. The initial overloading damage led to a largest ratio of the residual to maximum deflection as shown in Figure12c.

Besides the deflection, the cracks in all the beams except beam BR1 were extended upwards and the crack widths were enlarged (Figures 13a and 13b) during the fatigue loading. The maximum crack width in beam BR1 was found to have no increase probably because of the occurrence of few new cracks due to the tension stiffening effects of FRP sheets, which absorbed the fatigue-induced 
deflection increase. In beam BD1, however, no new cracks were detected due to the fatigue loading because the initial overloading prior to strengthening, which induced significant localized damage, so that the fatigue damage was concentrated at the major crack location.

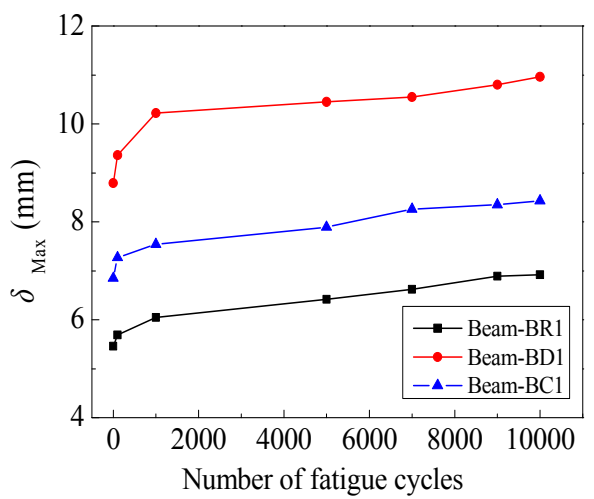

(a) Maximum Deflection

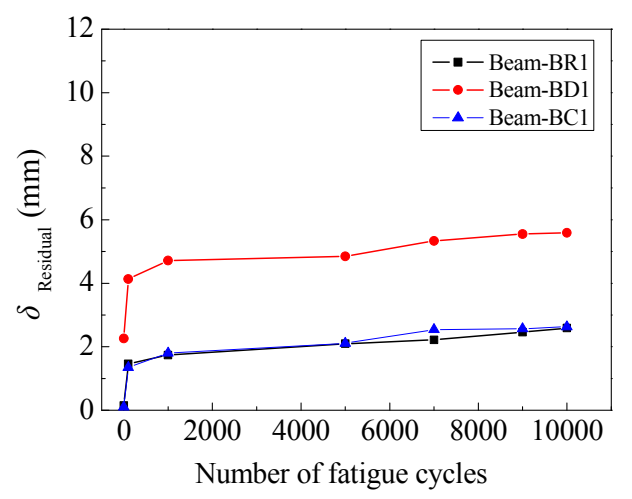

(b) Residual Deflection

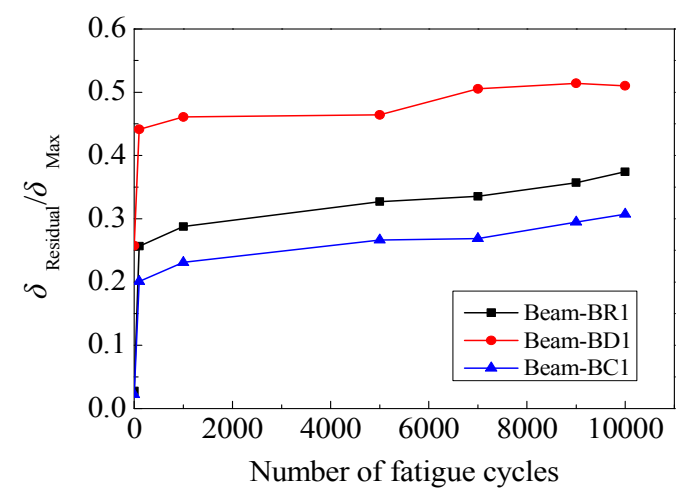

(c) Ratio of Residual Deflection to Maximum Deflection

Figure 12. Maximum and Residual Mid-span Deflections Versus Fatigue Cycles

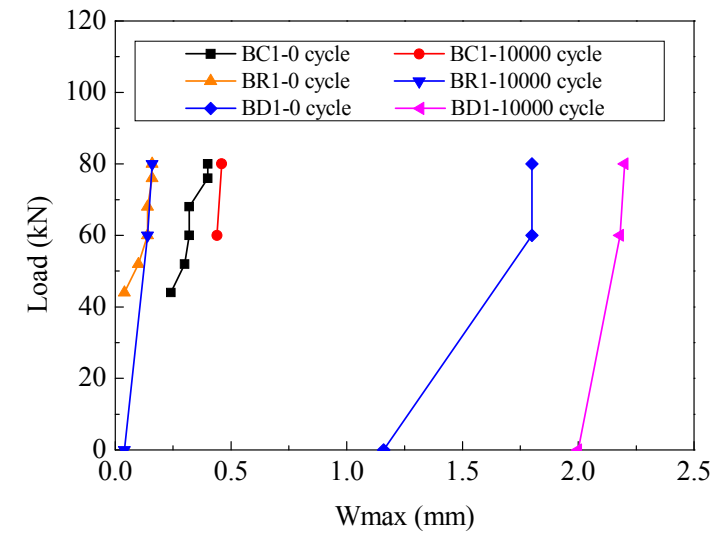

(a) Evolution of Maximum Crack Width

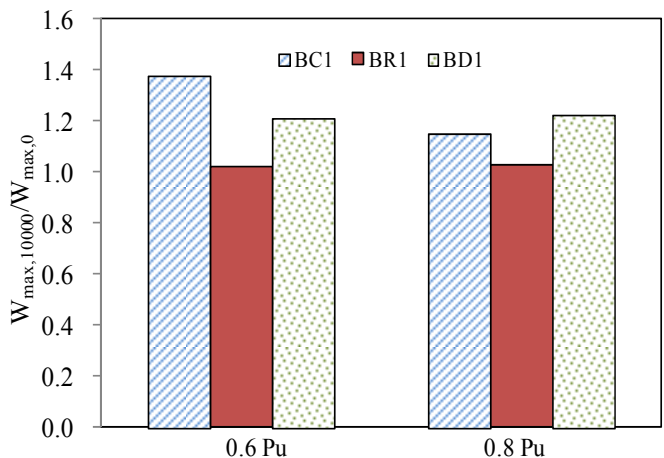

(b) Ratio of the Maximum Crack Width at the $10000^{\text {th }}$ cycle to that at the $0^{\text {th }}$ cycle

Figure 13. Maximum Crack Widths of Beams under Fatigue Loading 


\subsubsection{Strain development during fatigue overloading}

Figure 14 shows the strains in the concrete, the steel, and the CFRP laminate monitored at the mid-span location during the monotonic tests after a certain number of fatigue cycles. The tendency of strain development in concrete and steel reinforcement with the number of fatigue cycles coincided with that of the deflection development in all the beams (Figures 14a and 14b). However, for the two CFRP-strengthened RC beams BR1 and BD1, the strain development in CFRP exhibited two different tendencies (Figure 14c). Although the initial strain in CFRP was much larger in beam BD1, its increase was insignificant, while in beam BR1, the initial strain in FRP was relatively lower, its increase was very significant with the increase of the fatigue cycles. The insignificant increase in CFRP strain in beam BD1 was probably due to the debonding of FRP during the fatigue loading, which was caused by the localized widening of the major crack (Figure $7 d)$.

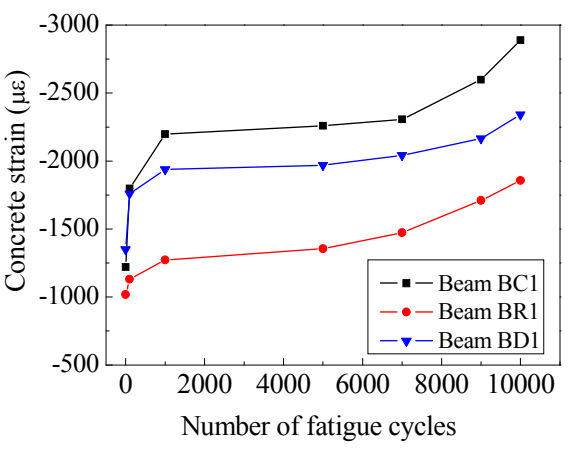

(a) Concrete Strain

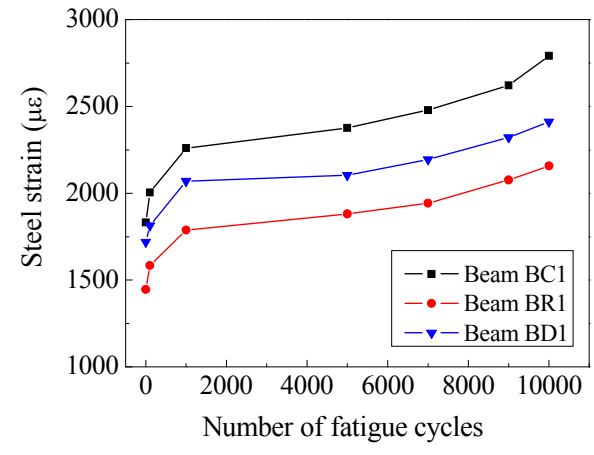

(b) Steel Strain

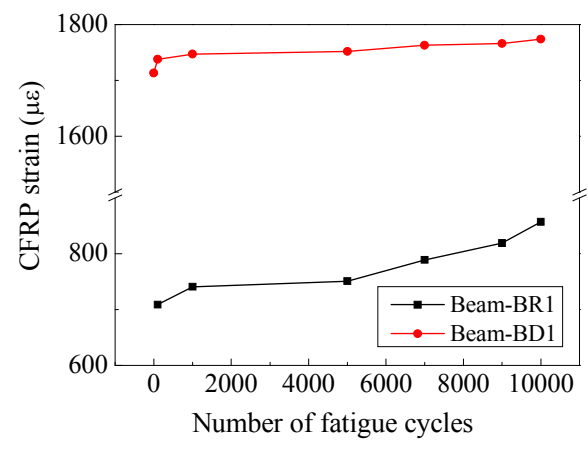

(c) CFRP Strain

Figure 14. Strains Development Versus the Number of Fatigue Cycles

\subsubsection{Post-fatigue monotonic static loading test results}

At the end of 10000 fatigue cycles, all the beams were loaded monotonically to failure to reveal the influence of cyclic overloading history on the strength performance of the bridge girder. Figure 15 shows the load-deflection responses of all the cyclically loaded beams. The post-fatigue ultimate strength of un-strengthened beam $\mathrm{BC} 1$ was $95 \mathrm{kN}$, which was $5 \%$ lower than that of the control beam BC0 due to the initial cyclic overloading damage. Similarly, a $4 \%$ decrease in the post-fatigue strength was observed for the CFRP-strengthened beam BR1 in comparison with the static strength of the beam BR0. However, the post-fatigue ultimate strength of beam BD1 was $4.3 \%$ higher than the static strength of beam BD0. This is probably due to the strain hardening phenomenon of the internal steel reinforcement. 
The post-fatigue ultimate strengths of CFRP-strengthened beam BR1 and FRP-strengthened initially overloaded beam BD1 were $124 \mathrm{kN}$ and $120 \mathrm{kN}$, respectively, which were $30 \%$ and $26 \%$ higher than that of the un-strengthened beam BC1. It is evident that the CFRP strengthening was still efficient in terms of the strength even under cyclic overloading. However, the post-fatigue ultimate deflections of the beams BR1 and BD1 were increased by $2.44 \mathrm{~mm}$ and $9.75 \mathrm{~mm}$, respectively, in comparison with that of their counterpart beams directly subjected to static loading (i.e., BR0 and BD0). However, under normal service loads, such a stiffness degradation mechanism is insignificant (Dong et al.[13], Ferrier et al.[14], Gheorghiu et al.[18]). Therefore the fatigue overloading caused much more damage to $\mathrm{RC}$ beams than normal fatigue loading due to the significant FRP debonding. As the member stiffness degradation and the widening of crack width may lead to severe serviceability problems, to keep the efficiency of the FRP strengthening during fatigue overloading, supplementary methods may be needed to suppress the debonding of FRP as well as to control the deflection and crack width of strengthened beams.

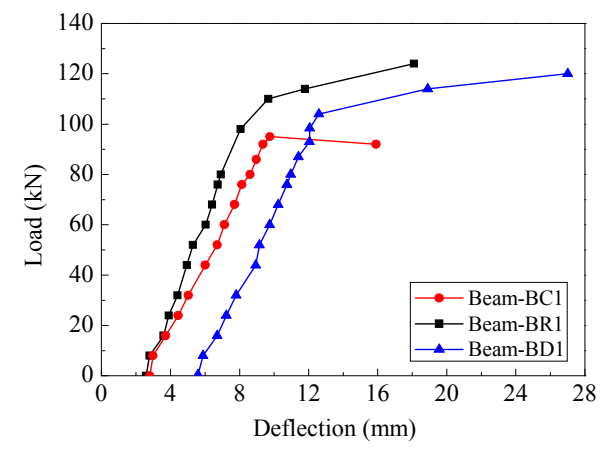

(a) Load-deflection Curves

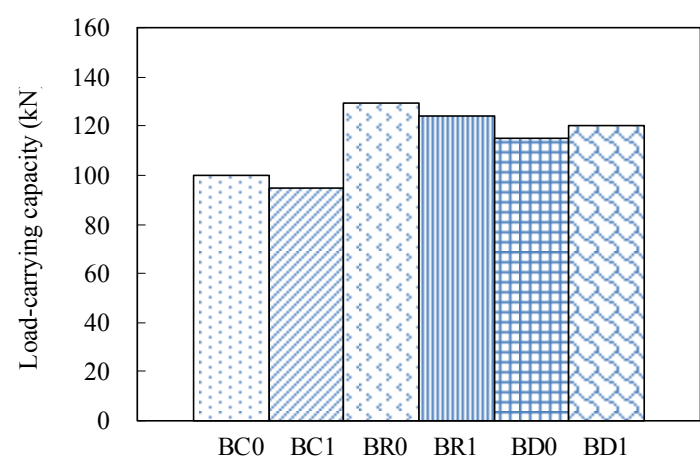

(b) Monotonic Static Test Strengths

Figure 15. Static Responses of Cyclically Overloaded Beams

\section{CONCLUSIONS}

An experimental study was conducted to investigate the static and fatigue behaviours of CFRP-strengthened RC beams subjected to overloading. Some of the RC beams had initial overloading damage. On basis of the experimental observations, the following conclusions can be drawn:

(1) FRP strengthening can improve the static load-carrying capacity of RC beams effectively. However, the overloading damage prior to the FRP strengthening may jeopardize the strengthening efficiency and change the failure mode of FRP-strengthened RC beams.

(2) If there is initial overloading damage prior to the fatigue strengthening of RC beams using FRP, the fatigue strengthening efficiency decreases due to the easier debonding of FRP during the subsequently cyclic overloading, which is attributed to excessive local deformation.

(3) The cyclic overloading also affects the post-fatigue static strength of both un-strengthened and FRP-strengthened RC beams. For un-strengthened and FRP-strengthened RC beams without initial overloading damage, the cyclic overloading history led to an about $5 \%$ decrease of the member strength compared to their static ones. However, if the RC beams were subjected to initial overloading damage, the post-fatigue static strength of FRP-strengthened RC beams even increased due to the strain hardening of internal steel reinforcement. 
(4) The cyclic overloading during the service of RC beams leads to significant member stiffness degradation and propagation of the crack widths. FRP strengthening could suppress effectively the maximum deflection since the stiffness contribution of FRP is more significant under an overloading condition and thus can improve the fatigue life of the strengthened beams. Under overloading condition, the fatigue life of RC bridge girders with or without FRP strengthening should be evaluated using the stiffness rather than the ultimate strength as a control index.

\section{ACKNOWLEDGMENTS}

The authors would like to thank the financial supports received from the National Natural Science Foundation of China (51378456), Qianjiang Talent Plan of Zhejiang Province (2012R10025), Natural Science Foundation of Zhejiang Province (LZ13E080001), the Key Science and Technology Innovation Team of Zhejiang Province (2010R50034), and the collaborative opportunity from The Hong Kong Polytechnic University through the research project G-YM26.

\section{REFERENCES}

[1] AASHTO, "AASHTO LRFD Bridge Design Specifications-3rd Ed", Washington D.C., U.S.A., 2004.

[2] Karabinis, A.I. and Kiousis, P.D., "Plasticity Model for Reinforced Concrete Elements Subjected to Overloads", Journal of Structural Engineering, ASCE, 2001, Vol.127, No.11, pp.1251-1256.

[3] Sun, X.Y., "Reliability-based Assessment of Reinforced Concrete Bridges in Commission and Strengthened Condition" (in Chinese), Dissertation Submitted to Dalian University of Technology in Conformity with the Requirements for the Degree of PhD, 2004.

[4] Gu, M., Tong, L.W., Zhao X.L. and Zhang, Y.F., "Numerical Analysis of Fatigue Behavior of Welded CFCHST-Joints", Advanced Steel Construction, 2014, Vol. 10, No. 4, pp. 476-497.

[5] Hersi, M.I., “Analysis of Bridge Failures in the United States”, Graduate Program in Civil Engineering of Ohio State University. U.S.A., 2009.

[6] Ji, B.H. and Fu, Z.Q., "Analysis of Chinese Bridge Collapse Accident Causes in Recent Years”, China Civil Engineering Journal, 2010, Vol.43, No.s1, pp.495-499. (in Chinese)

[7] Grace, N.F., Sayed, G.A., Soliman A.K. and Saleh., K.R., "Strengthening Reinforced Concrete Beams Using Fiber-reinforced Polymer (FRP) Laminates”, ACI Structural Journal, 1999, Vol. 96, No. 5, pp. 865-875.

[8] Pham, H. and Al-Mahaidi, R., "Experimental Investigation into Flexural Retrofitting of Reinforced Concrete Bridge Beams Using FRP Composites", Composite Structures, 2004, Vol. 66, No. 4, pp. 617-625.

[9] Esfahania, M.R., Kianoushb, M.R. and Tajaria, A.R., "Flexural Behaviour of Reinforced Concrete Beams Strengthened by CFRP Sheets", Engineering Structures, 2007, Vol. 29, No. 10, pp. 2428-2444.

[10] Wang, W.W., Dai, J.G. and Harries, K.A., "Performance Evaluation of RC Beams Strengthened with an Externally Bonded FRP System under Simulated Vehicles Loads", Journal of Bridge Engineering, ASCE, 2013, Vol. 18, No. 1, pp. 76-82.

[11] Wang, W.W., Dai, J.G., Harries, K.A. and Bao, Q.H., "Prestress Losses and Flexural Behavior of Reinforced Concrete Beams Strengthened with Post-tensioned CFRP Sheets", Journal of Composites for Construction, ASCE, 2012, Vol. 16, No. 2, pp. 207-216. 
[12] Xie, J.H., Huang, P.Y. and Guo, Y.C., "Fatigue Behavior of Reinforced Concrete Beams Strengthened with Pre-stressed Fiber Reinforced Polymer", Construction and Building Materials, 2012, Vol. 27, No. 1, pp.149-157.

[13] Dong, J.F., Wang, Q.Y. and Guan, Z.W., "Structural Behaviour of RC Beams Externally Strengthened with FRP Sheets under Fatigue and Monotonic Loading", Engineering Structures, 2012, Vol. 41, No. 8, pp. 24-33.

[14] Ferrier, E., Bigaud, D., Clément, J.C. and Hamelin P., "Fatigue-loading Effect on RC Beams Strengthened with Externally Bonded FRP". Construction and Building Materials, 2011, Vol. 25, No. 2, pp. 539-546.

[15] Breña, S.F., Benouaich, M.A., Kreger, M.E. and Wood, S.L., "Fatigue Tests of Reinforced Concrete Beams Strengthened Using Carbon Fiber-reinforced Polymer Composites". ACI Structural Journal, 2005, Vol. 102, No. 2, pp. 305-313.

[16] Al-Hammoud, R., Soudki, K. and Topper, T.H., "Fatigue Flexural Behavior of Corroded Reinforced Concrete Beams Repaired with CFRP Sheets". Journal of composites for construction, ASCE, 2011, Vol. 15, No. 1, pp. 42-51.

[17] Al-Rousan, R. and Issa, M., "Fatigue Performance of Reinforced Concrete Beams Strengthened with CFRP Sheets", Construction and Building Materials, 2011, Vol. 25, No. 8, pp. 3520-3529.

[18] Gheorghiu, C., Labossiere, P. and Proulx, J., "Fatigue and Monotonic Strength of RC Beams Strengthened with CFRPs", Composite: Part A, 2006, Vol. 37, No. 8, pp. 1111-1118. 